\title{
Enrichment of AISI 316L Steel Surface Layer with Rare Earth Elements Using Ion Beams
}

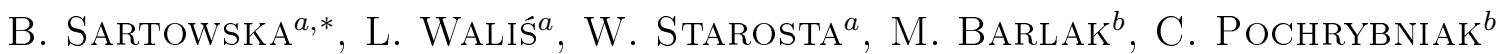 \\ AND E. KOWALSKA ${ }^{b}$ \\ ${ }^{a}$ Institute of Nuclear Chemistry and Technology, Dorodna 16, 03-195 Warsaw, Poland \\ ${ }^{b}$ National Centre for Nuclear Research, A. Sołtana 7, 05-400 Otwock-Świerk, Poland
}

\begin{abstract}
Enrichment of AISI 316L steel surface layers with rare earth elements was carried out using two methods with ion beam applying. The first one was the ion implantation with the doses in the range of $1 \times 10^{15} \mathrm{~cm}^{-2} \mathrm{up} \mathrm{to}$ $5 \times 10^{17} \mathrm{~cm}^{-2}$ where mishmetal (Ce+La) was used as the ion source. The second method was the high intensity pulsed plasma beams. The plasma pulses contained both ions/atoms of $\mathrm{Ce}+\mathrm{La}$ from the electrodes material (mishmetal). The pulse energy densities $\left(3 \mathrm{~J} / \mathrm{cm}^{2}\right)$ were sufficient to melt the near surface layer of the steel and introduce those elements into the surface layer. The aim of this work was to investigate the changes of stainless steel surface properties (morphology, rare earth elements concentration, presence of identified phases) after the rare earth elements addition with or without melting. Scanning electron microscopy, energy dispersion spectroscopy, and X-ray diffraction analysis were used for initial and modified surface characterisation. Grazing-incidence X-ray diffraction shows differences in the identified phase presence in the modified surface layer connected with the modification method.
\end{abstract}

DOI: 10.12693/APhysPolA.123.822

PACS: 52.77.Dq, 52.77.-j, 72.15.Eb, 81.65.-b

\section{Introduction}

Austenitic stainless steels are used in numerous industrial applications, due to their very good corrosion resistance - for example: nuclear and petrochemical industries, pulp and paper chemical, food and chemical processing and biomedical industries. But poor tribological and mechanical properties of austenitic stainless steels limited their applications in engineering fields. Engineering components made of these steels are in many applications operating in such extreme conditions that improvement of their high-temperature oxidation resistance is required. Mentioned improvement of austenitic stainless steels is very important from engineers' and constructors' points of view and can be realised using different surface treatment, for example: re-solidification techniques or enrichment of the surface layer with reactive elements or both. High oxygen affinity elements such as Y, $\mathrm{Ce}, \mathrm{La}, \mathrm{Er}$ and other rare-earth elements (REE) added to steels in small amounts can improve their resistance to wear [1], electrochemical corrosion [2] and high temperature oxidation $[2,3]$. REE can be added either during the steel making process or to the surface region of materials using different surface modification techniques such as: ion implantation [2, 3], sol-gel coating [4], pulsed plasma beams [5-8]. Ion and plasma beams can deliver energy and foreign ion species into the material.

When high intensity, short duration ion or plasma pulses hit a solid, they can modify the structure of its

*corresponding author near-surface region. Heating and cooling processes were of non-equilibrium type. Ion or plasma pulses can lead to various processes such as: mixing of the pre-deposited films with substrate material, formation of new stable or/and metastable phases, grain refinement.

In the present work we report the results of investigations of stainless steel surface properties (morphology, REE concentration, presence of identified phases) after the REE addition with or without melting.

\section{Experiment}

Austenitic stainless steel AISI 316L with the main elements concentration (in wt\%) $\mathrm{Cr}-16.3, \mathrm{Ni}-11.5$, Mo - 2.03, $\mathrm{Mn}-1.3, \mathrm{Cu}-0.3, \mathrm{Fe}-$ balance was used as the substrate for investigations. The mishmetal (MM) with the composition (in wt\%): $\mathrm{Ce}-65.3$, La -34.0 - and balance of $\mathrm{Fe}, \mathrm{Mg}$, and $\mathrm{Pr}$ was used as a REE source. The ratio of the elements concentration in MM was $\mathrm{Ce}(\mathrm{wt} \%) / \mathrm{La}(\mathrm{wt} \%)=65.3 / 34.0$ and was assumed to be $2: 1$.

REE were incorporated into one surface of steel samples by means of two different methods using ions beams. The first one was the ion implantation where mishmetal $(\mathrm{Ce}+\mathrm{La})$ was used as the ion source. The implantation energy was $65 \mathrm{kV}$, nitrogen atmosphere, ion doses in the range of $1 \times 10^{15} \mathrm{~cm}^{-2}$ up to $5 \times 10^{17} \mathrm{~cm}^{-2}$. The second method was the high intensity pulsed plasma beams (HIPPB). The plasma beams were generated in a rod plasma injector (RPI) operated in the deposition by the pulsed erosion (DPE) mode described in $[6,8]$. The plasma pulses contain both ions/atoms of $(\mathrm{Ce}+\mathrm{La})$ from the electrodes material (mishmetal) and nitrogen (the working gas). The pulse energy densities $\left(3.0 \mathrm{~J} / \mathrm{cm}^{2}\right)$ 
were sufficient to melt the near surface layer of the steel and introduce those elements into the surface layer. The cooling rate was estimated in the range of $10^{7}-10^{8} \mathrm{~K} \mathrm{~s}^{-1}$. The modification parameters were as follows: titanium rods coated with mishmetal tips as electrodes, nitrogen as the working gas and 3 pulses with the energy density $3.0 \mathrm{~J} / \mathrm{cm}^{2}$.

The samples were characterized for: initial and modified surface morphology observations with SEM DSM 942 (Zeiss, Germany); elemental concentrations determination of elements present in the surface layer with the Quantax 400 EDS system (Bruker, Germany) and material structure determination of the surface layer using the D8 Advanced (Bruker, Germany) diffractometer $\left(\omega=5^{\circ}\right.$, $\mathrm{Cu} K_{\alpha}$ radiation).

\section{Results and discussion}

The results of SEM observations of steel surface are presented in Fig. 1. On the surfaces of initial materials different size grains are visible. They are a result of steel making process - steel was delivered after hot rolling as the finishing treatment (Fig. 1a). After implantation the surface morphology was not changed - grain boundaries are still visible (Fig. 1b). After pulse modifications the initial grains boundaries disappeared and different morphological details (craters, cracks, droplets of melted material) were observed (Fig. 1c). These results show the first difference between the modification methods.



Fig. 1. Details of surfaces morphology of the AISI 316L steel: (a) initial, (b) implanted up to REE concentration $0.9 \mathrm{wt} \%$, (c) HIPPB treated and enriched with REE up to 1.0 wt\%.

The EDS spectrum of initial material shows the presence of main elements according to the elemental compounds of AISI 316L steel. A fragment of spectrum (0-2 keV) obtained for the initial material is presented in Fig. 2. The main visible peaks (according to the characteristic lines) were identified as

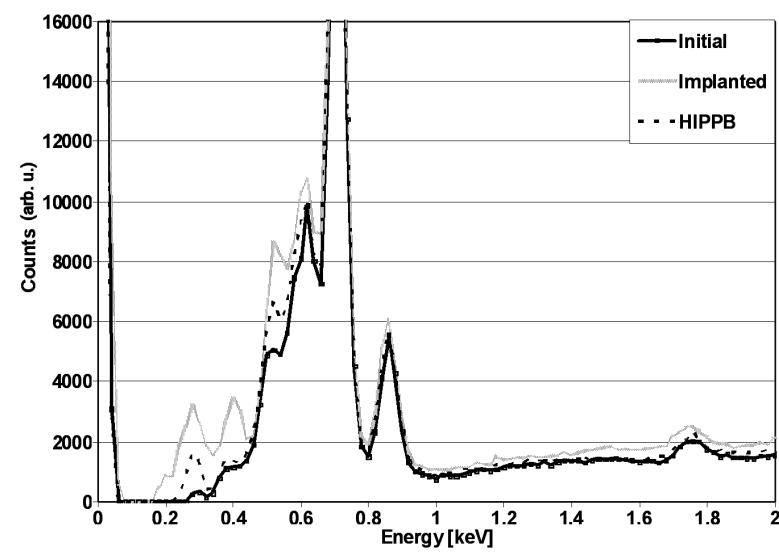

Fig. 2. EDS spectra of the AISI 316L steel: $(a)$ initial, (b) implanted, (c) HIPPB treated.

Cr with $L_{\alpha 1,2}$ at $572.8 \mathrm{eV}$ and $L_{\beta 1}$ at $582.8 \mathrm{eV}$, Mn with $L_{\alpha 1,2}$ at $637.4 \mathrm{eV}$ and $L_{\beta 1}$ at $648.8 \mathrm{eV}$, Fe with $L_{\alpha 1,2}$ at $851.5 \mathrm{eV}$ and $L_{\beta 1}$ at $718.5 \mathrm{eV}$, $\mathrm{Ni}$ with $L_{\alpha 1,2}$ at $705.0 \mathrm{eV}$ and $L_{\beta 1}$ at $868.8 \mathrm{eV}$.

The analysis of EDS spectra taken from the modified surface layers shows the difference between them and the initial material. The new peaks observed at low energies were identified as

$$
\begin{aligned}
& \mathrm{C} K_{\alpha 1,2} \text { at } 277 \mathrm{eV}, \\
& \mathrm{N} K_{\alpha 1,2} \text { at } 392 \mathrm{eV}, \\
& \mathrm{O} K_{\alpha 1,2} \text { at } 524.9 \mathrm{eV} .
\end{aligned}
$$

The presence of these peaks was connected with the elements used during the modification processes. The peaks observed at the energies of about $0.6 \mathrm{keV}$ and $0.8 \mathrm{keV}$ were stronger as compared with the initial material. Strengthening of the observed peaks was connected with the EDS signal from the other elements: La $M_{\alpha 1}$ line at $640.0 \mathrm{eV}$ and $\mathrm{Ce} M_{\alpha 1}$ line at $884.0 \mathrm{eV}$ and proved incorporation of La and Ce into the investigated surface layer. Thus obtained and presented EDS spectra confirmed enrichment of the steel surface layer with REE.

Samples with similar REE concentration (about $1.0 \mathrm{wt} \%$ ) were chosen for the phase identification.

The first two peaks of the grazing-incidence $\mathrm{X}$-ray diffraction (GXRD) spectra for untreated and modified materials are presented in Fig. 3. In the case of initial material peaks (111) and (200) were recorded and confirm the presence of austenitic structure of AISI 316L steel. In the case of investigations of the surface layer after ion implantation, no changes in the observed peaks position and shape were observed. It means that the austenitic structure remains after this modification. In the case of investigations of the surface layer modified with HIPPB, the surface layer was melted and the initial structure of steel was fully destroyed. During rapid solidification the process of freezing of the austenite took place. Solidification takes place when the REE ions are present in 


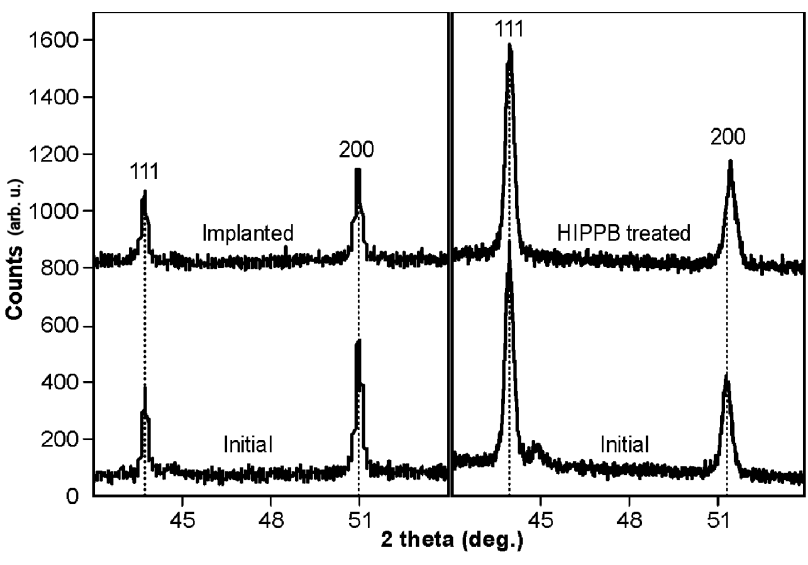

Fig. 3. GXRD spectra of the AISI 316L steel untreated, implanted, and HIPPB treated.

melts. So formed austenitic structures have different lattice parameters from those in the initial material. The identified peaks of austenite (111) and (200) were shifted towards lower angles which means that the lattice parameter of austenite increased. These results show the second difference between the modification methods.

\section{Conclusions}

1. Using two different methods with ion application the REE elements (here: $\mathrm{Ce}+\mathrm{La}$ ) were incorporated to the AISI $316 \mathrm{~L}$ steel.
2. Austenitic structures were present after modification processes.

3. In the case of ion implantation the initial austenitic structure of steel remains, but in the case of HIPPB processes the austenitic structure was frozen as a result of rapid solidification.

\section{References}

[1] F.J. Perez, M.J. Christobal, G. Arnau, M.P. Hierro, J.J. Saura, Oxidat. Met. 55, 105 (2001).

[2] C.M. Abreu, M.J. Cristobal, X.R. Novoa, G. Pena, M.C. Perez, R.J. Rodriguez, Surf. Coat. Technol. 158-159, 582 (2002).

[3] D.E. Alman, P.D. Jablonski, Int. J. Hydrogen En. 32, 3743 (2007).

[4] F. Riffard, H. Buscail, E. Caudron, R. Cueff, C. Issartel, S. Perrir, Appl. Surf. Sci. 199, 107 (2002).

[5] D. Cleugh, C. Blawert, J. Steinbach, H. Ferkel, B.L. Mordike, T. Bell, Surf. Coat. Technol. 142144, 392 (2001).

[6] J. Piekoszewski, Z. Werner, W. Szymczyk, Vacuum 63, 475 (2001).

[7] B. Sartowska, J. Piekoszewski, L. Waliś, J. Senatorski, M. Barlak, W. Starosta, C. Pochrybniak, I. Pokorska, Surf. Coat. Technol. 205, S124 (2011).

[8] B. Sartowska, Ph.D. Thesis, Institute of Precision Mechanics, Warsaw 2007. 